Original Research Article

\title{
Analysis on Ecological Protection of Urban Wetland
}

\author{
Pengfei Ye,Xiaoying Hao, Yifei Cao \\ School of Environment and Planning, Taiyuan City University of Science and Technology, Shanxi, China
}

\begin{abstract}
Urban wetland is an important ecological infrastructure of the city, which is an important natural system that depends on the sustainable development of the city. It has many ecological and social service functions. Urban wetland ecosystems are currently facing serious pollution, wetland area is reduced, biodiversity is seriously damaged, biological invasion led to the disappearance of the original species and other issues, for these issues proposed to create wetland parks, the establishment of nature reserves, the use of bioremediation of wetlands, Effective wetland information and evaluation system, strengthen legislation enforcement, regulate eco-tourism, strengthen international cooperation, change the mode of operation and other effective measures to restore and protect.
\end{abstract}

KEYWORDS: urban wetland ecological function protection measure

\section{Overview}

Wetland and forest, ocean and known as the world's three major ecosystems, is the most biological diversity of nature ecological landscape and human one of the most important living environment. Wetland has a variety of ecological functions such as flood control, regulating climate, conserving water sources, purifying water bodies and maintaining biological diversity. In all types of ecosystems, wetland ecosystems have the highest service value.

Urban wetland is an important part of urban ecosystem, and it has many kinds of ecological service functions which cannot be substituted by other ecosystems in the city. It is regarded as the best way to use terrestrial ecosystem. However, with the acceleration of the urbanization process, the urban wetlands have been severely damaged, thus greatly reducing the wetland support for urban economic and social sustainable development, so clearly understand the urban wetland service functions and to protect and restore urban wetlands is the current need to study the important issue.

\subsection{The concept of urban wetlands}

Wetland is a special waterway transitional ecosystem [1]. At present, there are many definitions of wetlands in the world. We use the definition of wetlands in wetlands, that is, wetlands are natural or artificial, long or temporary swamps, peatlands or watersheds, still or flowing, fresh water, Water, salt water, including low water depth of not more than $6 \mathrm{~m}$ of water. 'According to this definition we can see that the wetland is between the land and water between the transition zone, is due to surface flooding, or soil water saturation and the formation of a hidden natural complex.

Urban wetlands are the most important near-natural spaces in urban landscape units, including wetlands, lakes and wetlands, swamp wetlands and estuarine coastal wetlands, which are distributed in urban areas. Artificial, reflecting the diversity of the type and cause of the complexity, which constitutes the urban landscape in the plaque and corridor [2]. As the urban wetlands in the urban ecological construction has a special role, it is also known as the 'city of the kidney', 'natural species library.' 


\subsection{Classification and characteristics of urban wetlands}

\subsubsection{Classification of urban wetlands}

There are two types of natural wetlands and artificial wetlands. Among them, natural wetlands include rivers, lakes, estuaries, swamps, tidal flats, coral reefs and mangroves. Artificial wetlands include artificially constructed canals, Drains, reservoirs, artificial lakes, fish and shrimp farming ponds, ponds, rice fields and sewage treatment sites.

\subsubsection{Characteristics of urban wetlands}

Natural wetlands become patchy, the connection between plots is high, the degree of fragmentation is low, and the wetland habitat climate characteristics reflect the regional geography and climate characteristics, and the wetland hydrological condition is manifested by regional climatology, geology and topography Comprehensive characteristics.

Due to the impact of urbanization, urban wetlands have formed uneven distribution, small area, island wetland patches, and the connection between plots is not high, which increases the degree of fragmentation of habitats in wetlands. The In terms of climate characteristics. Urban wetlands have different climatic characteristics than urban areas, and are different depending on the urban functional areas.

Compared with natural wetlands, urban wetlands also have their own unique characteristics, especially with the acceleration of urbanization process, urban wetland ecosystem has been severely damaged. Wetland area decreased year by year

Artificial diversity, lack of biodiversity, and serious water pollution constitute the status of urban wetland ecosystem.

\section{Functions of urban wetlands}

The urban wetland not only has the ecological service function of natural wetland such as purifying water quality, regulating climate and so on, but also has a wide range of social service functions such as recreation and entertainment. Therefore, the protection of urban wetland ecology is the necessary measure of human survival and development and the guarantee of sustainable development the important condition. Urban wetlands are important urban ecological infrastructures. Has a large number of ecological and social services.

\subsection{The role of urban wetland water purification, flood control and water storage}

Wetlands play an extremely important role in purifying water quality, flood control and water storage.

With the development of urban industry, urban environmental pollution intensified, toxic substances into the wetlands, so that many urban water eutrophication, and in some wetlands appeared in the bloom, resulting in decreased water transparency, dissolved oxygen consumption, affecting the appearance of water and Aquatic organisms grow, and even endanger human health. The wetland system combined with the reed - water - green combination system and the Jiangbai - Shiju group were combined to remove the algal toxins and played a role in purifying the water quality.

At the same time, the wetland is the natural 'sponge' of waterlogging and flood control. It can absorb water from the surroundings and store water resources, adjust the water quantity, avoid the flood disaster in the city, and ensure the stable water supply of urban industrial production and residents' life.

\subsection{To improve the urban environment}

Urban wetlands affect regional microclimate. The transpiration of wetland plants, especially water plants and wet plants, keeps the city's air humid and improves urban environmental quality. In wetlands with urban forests, large amounts of rainfall are returned to the atmosphere through the transpiration and evaporation of trees, and then in the form of rainfall to the surrounding areas of urban forests. If the wetlands are destroyed, the area's rainfall will be reduced, the city's air will become dry, people feel very uncomfortable. For example: China's Tibet Lalu wetlands, not only to adjust the dry climate of Lhasa, but also day and night to create a lot of oxygen, which in the dry and arid plateau city was particularly valuable. Wetland plants can also absorb the atmosphere, and other toxic gases. According to the data show that wetland evaporation is 2 to 3 times the evaporation of the surface, the more evaporation, resulting in the lower the temperature in the wetlands, the strong evaporation of the near-formation air humidity increases, reducing the temperature in the surrounding areas, so as to achieve clean air, Effect, improve the role of urban environmental quality. 


\subsection{For the animals and plants to provide a variety of habitat}

Biodiversity is the basis for the survival and development of human society, and the protection of biological and genetic diversity has a special role in urban ecological construction. Freshwater wetlands have $40 \%$ of the world's species, of which $12 \%$ are animal species. Relying on wetland survival, reproduction of wild animals and plants is extremely rich, the richer biodiversity, the stability of its urban ecosystem is better. For example: Shanghai Chongming East tidal wetland is the only one in the wetland park adjacent to the migratory birds, there are more than 100 kinds of 200-300 million migratory birds perched there. Assuming that Shanghai's wetlands are lost, it is not just birds, but also Shanghai's civilized image and sustainable development.

In the world's freshwater species, half of the species are threatened by extinction, and wetlands are important genes for the conservation of wildlife populations as an important genetic gene for biological genetics. It is essential for the survival, screening and improvement of wildlife species. Home.

\subsection{To provide resources to develop hydropower}

Wetland animal and plant resources are extremely rich, can be used as a producer for the city to provide light industry, the main raw materials for urban residents to provide nutrition and delicious food, wetland animal and plant resources use also indirectly led the development of urban processing industry. In Hangzhou, people eat most of the fish is provided by Xixi wetlands, and many aquatic plants can also eat, for example: sea cauliflower, Brasenia schreberi and so on. Shore growth of mulberry silk to provide food, a good support for the silk industry in Hangzhou. Wetlands can also provide a variety of energy sources, from the wetlands directly dig peat for burning, wetland in the grass as a biomass can be used as fuelwood, wetlands in the huge fresh water resources is also human development of industrial and agricultural production and domestic water The main source. Urban wetlands also play a huge role in water supply, water storage and water supply. Such as Chaohu and Dongpu Reservoir, respectively, for the city of Hefei City, about 100 million tons of water and 7 million tons [3]. Wetlands also have important water transport value, hydropower development potential.

\subsection{For the urban residents to provide leisure and entertainment}

The diversity of landscape elements and species in urban wetlands makes many urban wetlands a good place for day-to-day leisure and vacationing of urban dwellers and foreign tourists. It is understood that only Hangzhou Xixi country wetland park after the opening of a project to attract a large number of tourists at home and abroad, according to the May 10, 2005 'Hangzhou Daily' reported '5.1' Tourism Golden Week, Xixi National Wetland Park In the first phase of the project after the opening of the 3.46 square kilometers area of tourists received nearly 52,000 people. In the subsequent May 17 day to attract tourists nearly 12,000 people ('Hangzhou Daily' May 19, 2005 reported) [4]. It can be seen that urban wetlands have become an important way to meet the spiritual life of human beings.

\section{Problems in the Development and Utilization of Urban Wetland}

\subsection{Urbanization is accelerating and area is reduced}

With the continuous expansion of the process of urbanization, a large number of domestic sewage, industrial waste water, municipal solid waste and construction waste, pesticides and fertilizers and other urban wetlands, so that wetlands are contaminated, the area gradually shrinking, landscape fragmentation Hangzhou since the 20th century, 90 At the beginning, with the expansion of urban construction area, Xixi wetland illegal building gradually increased, fill in the phenomenon of land reclamation occurred, to wetland area in 2002 only the liberation of the first $1 / 2$. In the Daqing wetland of northeastern China, due to the development of Daqing oilfield, urban construction and the production and community development of the residents in the wetland area, the original large area wetland has been divided and damaged to varying degrees, only the northwest of Dulbert County Department and the western part of Lindian County, has also maintained a large area of native wetland environment [5]. China's wetland is the most abundant, but it is severely damaged. The country has developed a 'zero loss' system for natural wetlands to protect wetland resources from further narrowing the area of natural wetlands.

Studies in the US Department of Agriculture show that urbanization involves both the encroachment and destruction of wetlands, and the United States has lost 58 percent of its wetlands. Since the development of the San Francisco area since the mid-19th century, due to the rapid population growth, mankind for the survival of the reclamation, urban construction, agricultural development and other measures to reduce the wetland area from the original $20,000 \mathrm{hm} 2$ to the 20th century, the 20th century, $2000 \mathrm{hm} 2$, In addition, not only the urban wetland area is rapidly decreasing, and wetland habitats are also seriously threatened. 


\subsection{Water pollution and eutrophication are increasing, reducing the diversity of wetland organisms}

With the development of the city, a large number of industrial waste water, domestic sewage and chemical fertilizers, pesticides and other harmful substances were discharged into rivers and other urban wetlands, causing serious damage to wetland biodiversity. Wetland resources of the predatory exploitation and excessive hunting. As well as the pollution of industrial wastewater and the introduction of species interference, not only seriously inhibit the wetland resources potential and ecological function play, but also caused the loss of biodiversity and wetland habitat deterioration. The discharge of industrial waste water and the loss of pesticides directly lead to the enrichment of aquatic organisms and the accumulation of harmful substances such as heavy metals in aquatic organisms. The discharge of domestic sewage and the loss of chemical fertilizers lead to eutrophication of water bodies and the types of plankton Single, and even some algae explosive growth, so that the entire habitat deteriorated. At the same time coastal areas due to industrial wastewater and urban sewage directly row the sea. Resulting in frequent occurrence of red tide, so that a large number of fish and shellfish died in serious polluted areas, such as some of the intertidal zone immediately adjacent to the sewage outfall, and sometimes even lead to extinction.

\subsection{Biological invasion, the original species disappeared}

The diversity, visibility and visibility of urban wetlands are the basis of urban wetland leisure tourism. In recent years, due to the diversity of urban wetland landscape requirements, a large number of alien species were blindly introduced, resulting in a number of native plants in the case of competition, but a large number of deaths or even extinction. For example, in the 1930s, Yunnan's Dianchi Lake in the introduction of water hyacinth as a bait, the large number of breeding in Dianchi Lake once a serious water eutrophication, resulting in a lot of native species extinction, from the 60 's to the 90 's 30 during the year, the fish dropped from 68 to 30 species. A large number of invasive alien species, but also to the original wet food chain has been destroyed, so that wetland ecosystem resistance to interference capacity decline, not only the wetlands of the ecological environment deteriorating, but also to wetland natural species library forever lost these valuable gene. Another example: Beijing Han stone bridge wetland, balm grass and wild soybean invasion of its coverage once reached 95\% [6], making the local plant reed growth is limited, and even death, seriously damaged the original wetland ecosystem structure.

\subsection{Excessive mining, lake sedimentation}

As the urban wetlands bear a city ecology and cultural tourism attractions of the particularity, it is required in the wetlands to build many humanities and folk attractions and public service facilities, the construction of these sites must occupy a certain land, in the absence of sufficient land, People had to build a lake, excessive excavation may lead to increased wetland swamps, shrinking water, water reduction, lake sedimentation, resulting in increased population competition, biological diversity. There are some because people blindly pursue economic interests lead to shrinking wetland area. For example: Sichuan Ruoergai wetland, the original 50 million hectares of peat swamp, if the use of good will be a huge reservoir, can continue to transport water for the Yellow River, but also a natural sand barrier to protect the ecological surroundings. However, in the 1970s, in order to blindly pursue the development of animal husbandry, people will be peat marsh water drained to expand the grassland area, improve the carrying capacity, resulting in the proliferation of rabbits, a large area of grassland serious degradation, Hard to restore to the original look.

\subsection{Man-made damage, functional decline}

Urban wetlands are the ecological barriers of the city and have a high leisure travel value. But unfortunately, in the development and utilization of tourism and tourism in the process of human destruction is very serious, many of the city's riparian coast and the coast was piled up into a high cement wall, artificially bound the river, river and sea water, affecting the flood, On the other hand, many projects (such as the coastal landscape road) almost equal to the beach, the coast, in the destruction of the landscape at the same time, but also interfere with the beach development and waterfowl, the development of the beach, the landscape is not conducive to flood control, Of habitat and foraging. In addition, in some urban fringe wetland nature reserves, there are still many illegal activities, such as fried mountain quarry, encircling birds and birds, leading to the decline in the number of birds, seriously affecting the urban wetland tourism and tourism functions [7].

\section{Protection of urban wetlands}

A wetland that is not disturbed by unusual natural and human factors is in good health because of its diversity of species, structural complexity, functional integration and resistance to external forces. When the external disturbance is more than the repair capacity of the wetland, the wetland health will deteriorate, the function will degrade, and then affect the regional environment. Therefore, we must pay attention to the protection and restoration of urban wetlands, 
and develop forward-looking planning concepts and scientific planning measures and methods to protect urban wetlands.

\subsection{To create a wetland park, the establishment of nature reserves}

City Wetland Park can enhance the taste and competitiveness of the city. Since February 2005, the State Forestry Administration approved Hangzhou Xixi Wetland Park to become China's first national wetland park, all over the city have been actively creating wetland park. November 2005, Jiangsu Yangzhou Jiangyan Qin Lake Wetland Park through the State Forestry Administration assessment, as China's second national wetland park; September 25, 2006, Ningxia Yinchuan National Wetland Park is also officially listed as the Yellow River Basin and the The first national wetland park in the western region. May 2005, the Ministry of Construction approved the Beijing Haidian District Cuihu Wetland Park, Wuxi Mayor Guangxi Wetland Park, Changshu City still Lake Wetland Park, Shaoxing City Mirror Lake Wetland Park, Dongying City, Lake City Wetland Park, Dongping County rice Tuen Wetland Park, Changde City West Dongting Lake Castle Peak Lake Wetland Park, Tangshan Nanhu Wetland Park and Huaibei Nanhu Wetland Park for the National Urban Wetland Park. Currently there are constructions of Nanjing Qinhuai River Wetland Park, Shanghai Chongming Dongtan Wetland Park, Shaanxi Qichuan River Wetland Park 2 O more than wetland park [8]. The creation of the city wetland park not only provides a better protection for the protection and utilization of wetlands, but also provides a good recreation and entertainment for the local residents, but also brings great economic benefits. The establishment of wetland park, the real realization of the ecological benefits, social benefits and economic benefits of the three goals. At the same time, it is necessary to build a natural reserve within the wetland park, which is an effective measure to prevent the reduction of wetland, the deterioration of wetland ecological environment and the degradation of ecological function.

\subsection{Bioremediation Wetlands}

Wetland bioremediation technology, also known as wetland treatment system, is controlled by the sewage body to control the growth of large aquatic plants (such as: reed, calamus and lotus) and filter feeding fish (such as: silver carp Fish and bighead carp) on the wetlands, so that it is often in a saturated state, the sewage in a certain direction through the water-resistant plants and soil and the combined effect of fish to be purified [9]. In the restoration and establishment of wetland vegetation, should be based on native plants, supplemented by a certain foreign species, but must consider the introduction of the risk. Practice shows that bioremediation of wetlands is an efficient and inexpensive means of wetland protection, while the wetland water quality can be purified while also bringing the landscape ornamental value and educational significance.

\subsection{Establish wetland information systems and health assessment systems}

In order to develop the scientific wetland utilization and protection strategy and realize the sustainable development of wetland resource utilization, it is urgent to quantify and study the present situation and dynamic changes of wetland. The 3S (RS, GIS and GPS) technology can be used for wetland research and reasonable evaluation of wetland Change and forecast future wetland development trends to provide strong technical assurance. At present, $3 \mathrm{~S}$ technology has been widely used in wetland resources survey, wetland resource dynamic change monitoring, wetland resource mapping and wetland landscape pattern analysis and other aspects and achieved some results, but in wetland biodiversity, wetland environmental benefits, wetland boundary determination and Wetland resources management and other aspects of research less, need to further accelerate the study. Wetland health refers to the whole wetland ecosystem is complete, stable and sustainable development, and resistance to adversity, while wetlands can also provide a sound ecological services and viewing functions. In this way, ecological characteristics (such as wetland biological species, population characteristics, community characteristics and biodiversity), ecological functions (such as water supply capacity, selfpurification capacity and climate regulation capacity) and ecological environment (such as water eutrophication, The surrounding population and the degree of satisfaction with the masses) and other three aspects of the establishment of wetland health assessment system to assess the health status of wetlands, so as to develop a corresponding wetland protection strategy cited [10]. In 2008, the 12th World Wetland theme was 'healthy wetlands, healthy humans'. It can be seen that the establishment of wetland health assessment system in urban wetlands is imminent.

\subsection{To strengthen the legislative law enforcement, standardize eco-tourism}

China does not yet have a special law to protect wetlands, which has brought difficulties to the scientific management and rational use of wetlands. The sound wetland protection law has a positive effect on the development and management of wetland resources, wetland ecosystem protection and social sustainable development. Therefore, to speed up the legislative pace, to provide a legal basis for wetland protection is one of our key work to protect wetlands. At present, the 'Regulations on the Administration of Wetland Protection' has been determined by the national legislature as a legislative plan in recent years. Some local wetland laws and regulations, regulations in the country in front of, 
for example: 'Hangzhou Xixi Wetland Park Protection and Management Regulations' [11] on the wetland planning, construction, protection, utilization, management and legal aspects Made a detailed description. In recent years, with the rapid development of eco-tourism, people in sightseeing at the same time often overlooked environmental protection and habitat maintenance, indiscriminate fruit paper scraps, arbitrary picking flowers and trees, and even damage the phenomenon of wild animals have occurred. Therefore, while strengthening the legislation, we must also regulate the eco-tourism, the urban wetland tourism environment capacity, activity area, activities and opening time to make strict and specific provisions, and wetland ecological environment for regular monitoring to ensure its In a stable state.

\subsection{To strengthen publicity, public participation}

The protection and development of urban wetlands should be attended by all the members of the society. The government departments should make full use of the natural scenery of the wetlands, the protection of animals and plants, such as network, television, newspapers, city district publicity columns and bus advertisements. The Government can also learn from the Hong Kong Mai Po Wetland Park model, which organizes young students to visit the wetlands, conduct popular science and tourism, and the government purchases tickets for them. Shanghai to protect the Huangpu River estuary Jiangwan a piece of about 5000 acres of secondary wetland ecological zone, through the form of network communication to attract social attention, and organize volunteers to protect the wetlands, called on experts to express their views, and with the local real estate developers Fen And asked the government planning department to revise already approved plans to protect precious wetland resources through advocacy and public participation.

\subsection{To strengthen international cooperation, change the mode of operation}

On the one hand, on the one hand, the Chinese mainland cities must learn from the experiences of cities such as Australia and Hong Kong in the protection, development and management of urban wetland tourism resources. On the other hand, domestic cities should also be involved in wetland tourism, Protection and cooperation, such as cooperation in wetland parks, waterfowl sightseeing and habitat protection, wetland science, and cooperation and cooperation with international organizations such as the World Wildlife Conservation Organization, World Wide Fund for Nature, World Tourism Organization and other organizations [12]. In the financing model should be used internationally popular BOT (Build-Operate-Transfer, namely: the construction of a transfer of a transfer) model. The construction of the Qinhuai River Wetland Park that imitate Hong Kong and Japan took the lead in the domestic use of this model, the first by the local government to raise private capital, and then commissioned the construction of the project company, while the project company has the right to operate the wetland park, the government given the project company Of the compensation to the agreement after the operating period, the project company will be transferred to the government free of charge. This model not only reduces the financial burden of the government, but also makes the wetland park has a better management and management.

\section{Conclusion}

Urban wetland system is an important ecological infrastructure of the city, and the protection of urban wetlands requires the participation of the whole society. This is also the responsibility and obligation that the public should bear. Therefore, the relevant departments must increase the publicity of wetland protection, so that the public awareness of the importance of wetlands, enhance the public to cherish the wetlands, love the awareness of wetlands.

\section{$\underline{\text { References }}$}

1. Shen Wanbin, Zhao Tao, Liu Peng. Artificial wetland environmental economic value evaluation and case study [J]. Environmental Science Research, 2005,2 (18): 70-73.

2. Sun Guangyou, Wang Haixia, Yu Shaopeng. Advances in urban wetland research [J]. Advances in Geography, 2004, 23 (5): $94-$ 100 .

3. Zhai Chengjiang, Han Jiutong. Protection of urban wetlands practice and discussion [J] Anhui Agricultural Sciences, 2006,34 (11): 2501-2502.

4. Chen Jiuhe and Xu Caidi. Urban edge wetland tourism environment ecological capacity research one by one to Hangzhou Xixi National Wetland Park as an example [J]. Science and Technology Bulletin, 2006, 22 (5): 714-718.

5. Li Jingwen, Shang Hongxi. Plant diversity of Beijing wetland and the impact of xerophyte invasion on biodiversity [J]. Science and Technology and Engineering, 2006, 18 (6): 2858-2863.

6. Chen Jinhua, Li Hongbo, Huang Anmin, Yang Wenqi. Leisure tourism function of urban fringe wetland [J]. Resource Development and Marketing, 2006, 22 (4): 386-388.

7. Liu Guoqiang. China's wetland park planning, construction and management of thinking [J]. Wetland Science and Management, 2006, 2 (3): 21-24. 
8. R. Dai Zhisi. Qian Yi, Zhao Feng, Hao Jiancheng, Zhu Xinyuan, translation. Natural control system for water pollution [M]. Beijing: National Environmental Protection Agency, 1986.

9. Shi Yuan, Zhou Qing. China's wetland ecological problems and protection countermeasures [J]. Chinese Agricultural Science Bulletin, 2006, 22 (6): 337-340.

10. Sang W. On China's wetland management and protection legislation [J]. Wetland Science and Management, 2006, 2 (3): 50-53.

11. Chen Jinhua, Li Hongbo, Huang Anmin, Yang Wenqi. Leisure tourism function of urban marginal wetlands [J]. Resource Development and Marketing, 2006, 22 (4): 386-388.

12. http://www.Daqingshidi.Com/news. 